\title{
Disability concept of visual impairment
}

Cunhat Hiago*

Research Institute for Special and Inclusive Education

*Corresponding author's email: cunhathiago@gmail.com

To overcome the difficulties that people with disabilities face, interventions to remove environmental and social barriers are necessary. These plural and interdisciplinary dimensions are studied by disability studies. The studies take into account the biological, bodily, social, and subjective aspects of disability. We present the characteristics of the visual handicap according to these areas with a focus on children with visual impairments.

For biological aspect, visual impairment is defined on the basis of visual perceptions of acuity and field. When the acuity, measured after correction on the best eye, is less than three tenths or the visual field is less than 20 , they are visually impaired. Severe visual impairment is acuity between one tenth and one twentieth. A person is legally blind if their acuity is less than one twentieth, but the situations are diverse: some have a vision, a bright or colored perception, while others have none. Visual 
impairments in children may be due to various factors: birth defects, accidents or, in the case of economically underdeveloped countries, deficiencies, childhood illnesses and lack of access to care.

For bodily aspect, visual impairments generate disabilities which differ according to the severity of the impairment, the degree to which the disability is declared and associated disabilities. Studies have shown that children with blindness and cognitive development problems are correlated with blindness, but with intellectual development, similar to that of clairvoyants. They also affect sensorimotor development, therefore the body diagram (the perception of one's body, movements and the body in space) and posture. Adaptation to the environment requires compensation that leads to significant fatigue, but can also trigger musculoskeletal disorders. A series of attitudes are more frequent in people with severe visual impairments, such as turning their heads to strain their ears during a conversation, which influences social interactions. Early management is crucial to avoid the development of associated disorders and allows blind and partially sighted young people not to accumulate developmental delays. 
For social aspect, visual impairments are related to the dynamics of interactions with other people, which are linked to environmental factors. It has been shown that children with disabilities encounter hostile or humiliating reactions from their peers or adults, and that they are affected by various forms of mistreatment. Visual impairments complicate social relationships, preventing the perception of nonverbal cues necessary for communication. In children, this can prevent or distort their understanding of social norms, reactions caused by behavior or play by their peers. However, in an inclusive school, these differences in interactions fade. Children develop original approaches to communication to deal with these problems, such as verbal knowledge without concrete perceptual knowledge and which then lend themselves to all kinds of distortions. They would be part of a process integration into society and making it possible to structure fragmented and multimodal perceptions, especially in children with profound visual impairments.

For subjective aspect, visually impaired children define themselves by their similarities with their peers, and this despite the many discriminations experienced which can generate frustrations and have negative effects on their self-esteem and their possibilities to project themselves into the future. The development of this trust and of adequate mental images through experience is one of the major 
challenges in the care of visually impaired children. We call mental image, the personal representation of an object or concept. When there are residual visual perceptions, they are used to give the maximum visual information allowing these representations to be in harmony with the environment. Finally, certain situations generate significant stress. This is particularly the case with displacement or unknown situations.

\section{References}

Banovic N., Franz R. L., Truong K. N., Mankoff J. \& Dey A. K. Uncovering information needs for independent spatial learning for users who are visually impaired. In ACM SIGACCESS (2013), 24.

Brock A. M., Truillet P., Oriola B., Picard D. \& Jouffrais C. Interactivity improves usability of geographic maps for visually impaired people. HumanComputer Interaction 30, 2 (2015), 156-194.

Cass H. Visual Impairment and Autism: Current Questions and Future Research. Autism 2, 2 (1998), 117-138.

Dale N. \& Salt A. Social identity, autism and visual impairment (VI) in the early years. British Journal of Visual Impairment 26, 2 (2008), 135-146. 
Datta P. Self-concept and vision impairment: A review. British Journal of Visual Impairment 32, 3 (2014), 200-210.

Diamond K. E. The development of social competence in children with disabilities. In Blackwell handbook of childhood social development, P. K. Smith C. H. Hart, Ed., Blackwell handbooks of developmental psychology. Blackwell Publishing, 2002, 572-587.

Dramas F., Macé M., Katz B. F. \& Jouffrais C. Object Localization System for the Blind: Designing a User-Centered Auditory Interface. In CSUN Conference (2010).

Holt R., Moore A.-M. \& Beckett A. Together Through Play: Facilitating Meaningful Play for Disabled \& Non-Disabled Children through Participatory Design. In Inclusive Designing: Joining Usability, Accessibility, and Inclusion, Springer-Verlag (2014).

Kinoe Y. \& Noguchi A. Qualitative Study for the Design of Assistive Technologies for Improving Quality of Life of Visually Impaired. In Human Interface and the Management of Information. Information and Knowledge in Applications and Services, S. Yamamoto, Ed., vol. 8522 of Lecture Notes in Computer Science. Springer International Publishing, 2014, 602-613. 
McGaha C. G. \& Farran D. C. Interactions in an inclusive classroom: The effects of visual status and setting. Journal of visual Impairment and Blindness 95, 2 (2001), 80-94.

Pietrzak T., Martin B., Pecci I., Saarinen R., Raisamo R. \& Jarvi J. The micole architecture: Multimodal support for inclusion of visually impaired children. In ICMI 2007 (2007), 193-200.

Susanto, Susanto, and Deri Sis Nanda. "TEACHING AND LEARNING ENGLISH FOR VISUALLY IMPAIRED STUDENTS: AN ETHNOGRAPHIC CASE STUDY." English Review: Journal of English Education 7.1 (2018): 83-92.

World Health Organization, visual disturbances and blindness (H53-H54), 2015. Adiguzel T., Capraro R. M. \& Willson V. L. An Examination of Teacher Acceptance of Handheld Computers. International Journal of Special Education 26, 3 (2011), 12-27. 